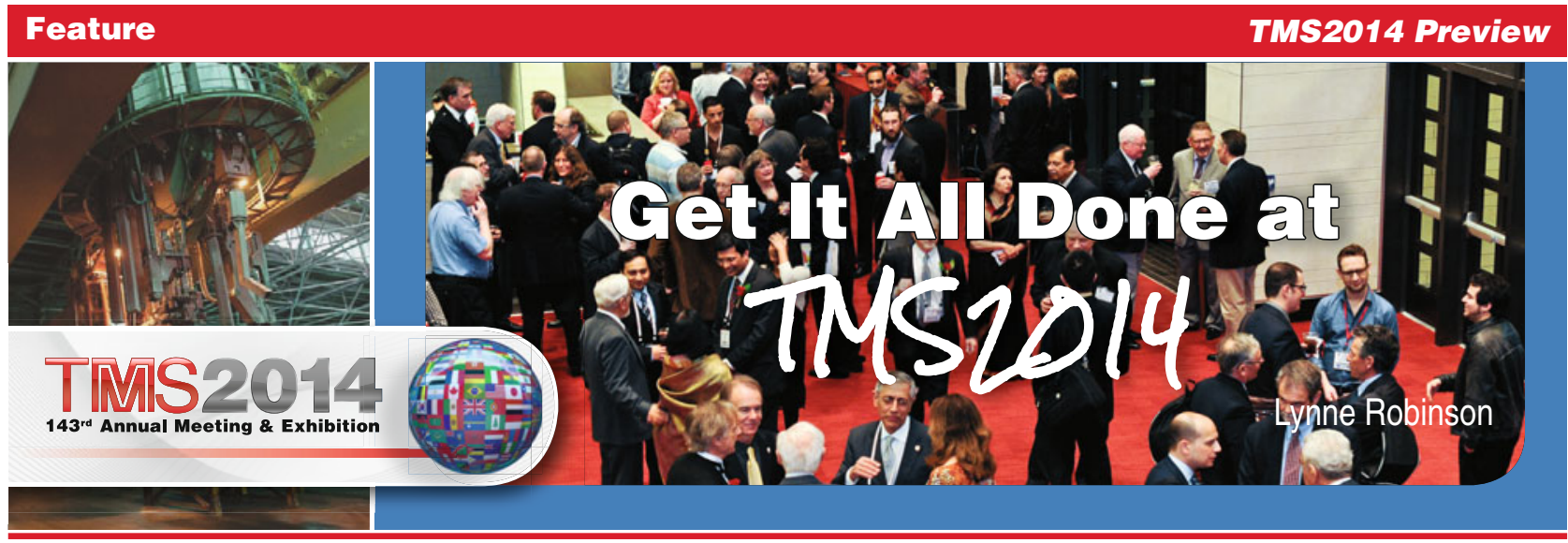

From Neville Moody's vantage point, all roads in the minerals, metals and materials community eventually lead to a TMS annual meeting. "It's a unique meeting among materials societies, since it serves a core foundation of physical and mechanical metallurgy, while embracing new disciplines and directions," he said. His biggest challenge, as the Programming Direc-

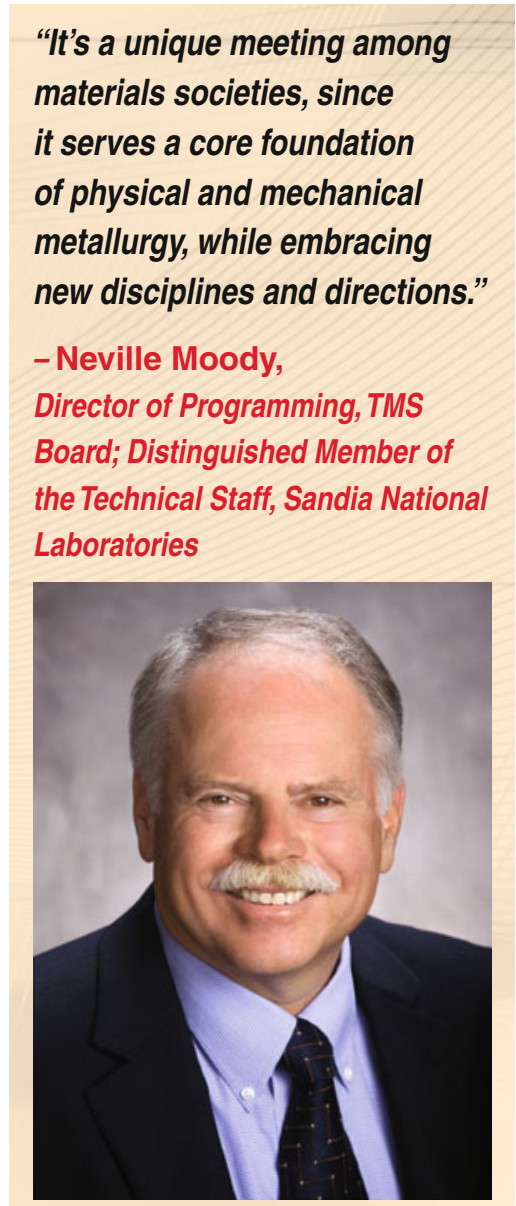

tor on the TMS Board, is to maintain TMS's signature balance "between science and engineering, as well as cutting-edge materials and important metallurgical problems. We need to continually refresh content to provide value to new professionals and core membership alike, providing a 'home' where they can share their knowledge, research, and learning," he noted.

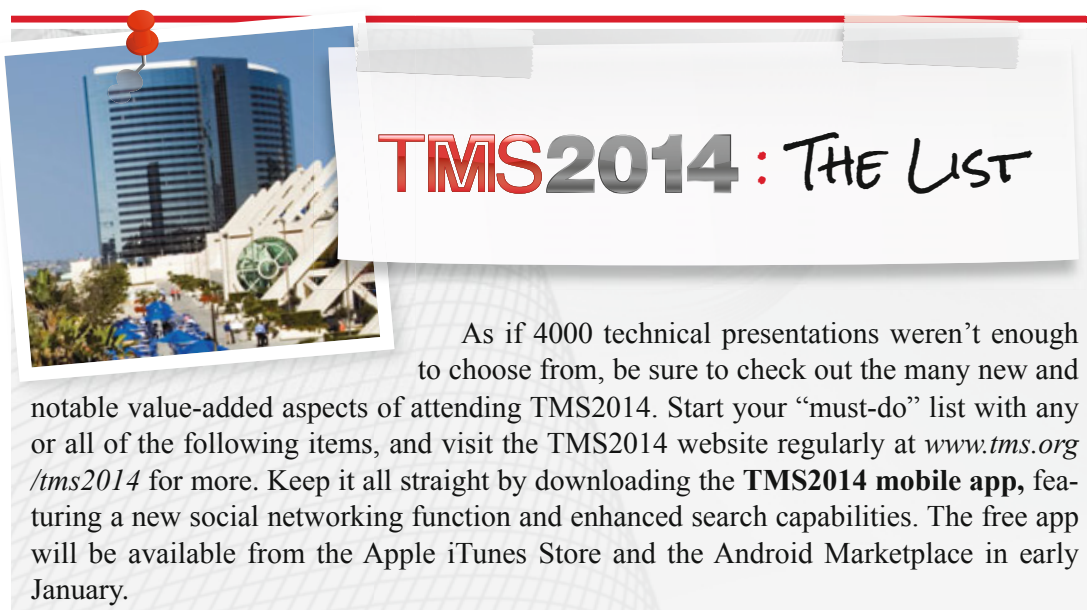

Deadine For TMSZO14

REgistration DISCOUNT: JanuARY 17, 2014

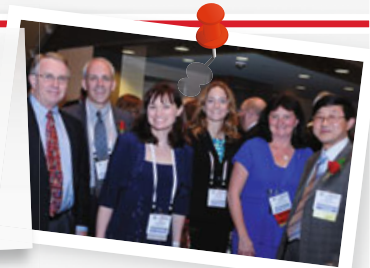

Don't risk missing a moment of TMS2014, February 16-20, in San Diego, California. Act today to ensure that you:

- Receive a significant discount on the meeting fee and the best rates for housing. Register by January 17, 2014 at www.tms.org/tms2014.

- Secure your visa, if you are an international traveler to the United States. This process can take up to three months. The TMS2014 website provides an array of resources to assist with this, including generation of an official visa invitation letter.

- Build your case to your employer by using the TMS2014 Justification Tool Kit, available on the website.

- Preview the TMS2014 Exhibition online to begin developing your itinerary for exhibit visits or to determine what spaces might still be available for your company.

Check the TMS2014 website often at www.tms.org/tms2014 for programming updates and other meeting related news. 


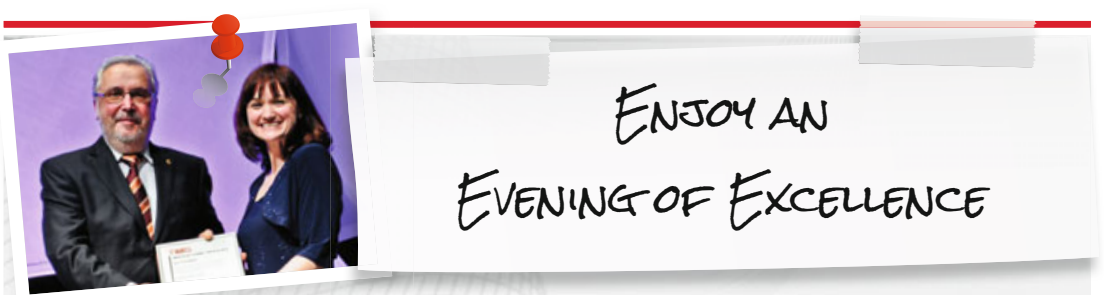

Offering a rare opportunity to see and hear some of the most influential figures in the minerals, metals, and materials community at the pinnacle of their careers is the 2014 TMS-AIME Awards and Honors event, set for Tuesday, February 18. The Awards and Honors Ceremony, open to all TMS attendees, will take place immediately prior to the Awards and Honors Banquet, which is a separate ticketed event. "Our goal for this year's ceremony was to heighten the gravitas," said Elizabeth Holm, 2013 TMS president. "By highlighting it in a theater-style venue, we can ensure that all eyes are turned to our award recipients as they receive TMS's highest honors. This year's ceremony will also be hosted and presented by some of our most eminent members, with the TMS Board of Directors also providing recognition. For our more senior members, we believe it will offer a memorable, moving occasion to celebrate the excellence of their colleagues. We hope members early in their careers will take advantage of this chance to congratulate mentors and be inspired to strive for similar heights themselves."

Those who have registered for the banquet will move to a nautical-themed celebra-

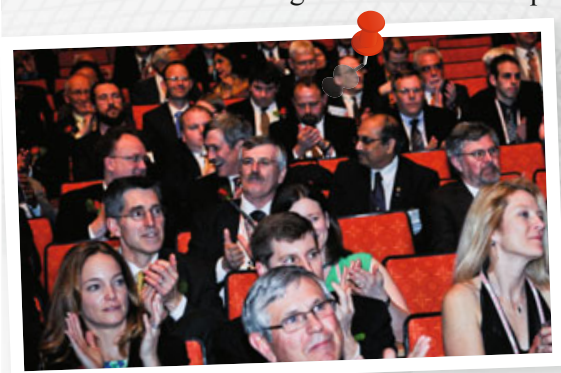
tory dinner, featuring a private concert with Scottish fiddle legend, Alasdair Fraser, and renowned cellist, Natalie Haas. "The evening is shaping up to be a treasure, offering experiences and camaraderie that you simply can't get anywhere else," said Holm. Banquet reservations must be made through the TMS2014 registration form hosted on the TMS2014 website.

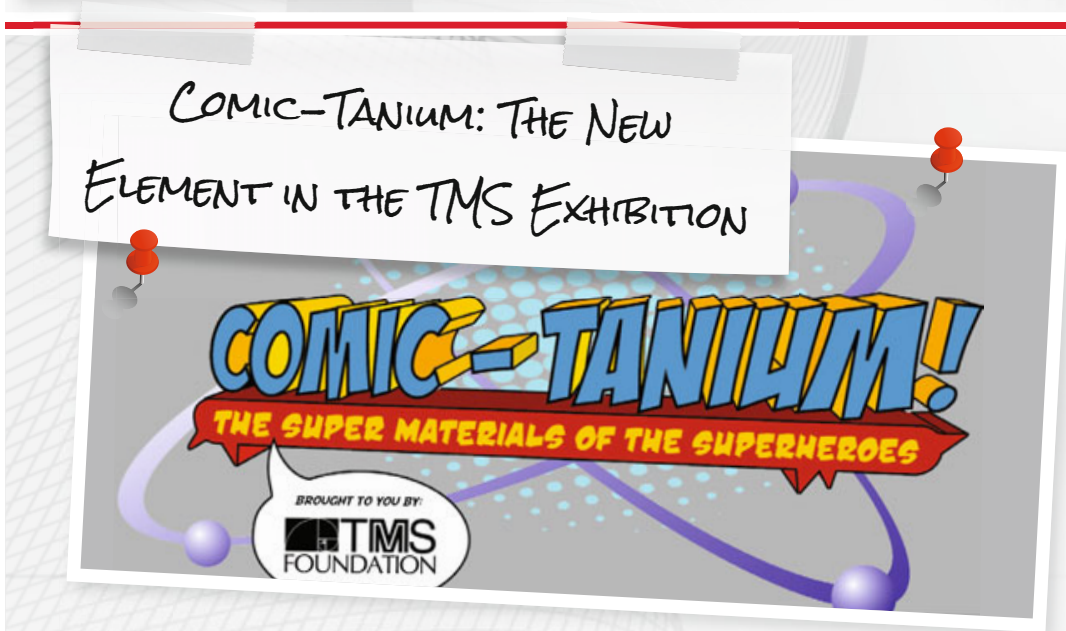

See for yourself how Batman, Iron Man, Spider-man and other favorite comic characters use minerals, metals, and materials science and engineering to boost their powers and save their worlds. Check out COMIC-tanium: The Super Materials of the Superheroes, a major outreach initiative of the TMS Foundation and the Toonseum, one of only two museums in the United States dedicated to the cartoon arts. Set to debut at the TMS2014 Exhibition, COMIC-tanium draws from the serious science behind popular comic sagas to educate and inspire young people, while raising public awareness of the impact of materials research and development on society. TMS2014 attendees will have the opportunity to provide feedback on COMIC-tanium before it travels next to the USA Science \& Engineering Festival on April 26 and 27, and then opens officially at the Toonseum in Pittsburgh later in the year..
Attracting that content to the TMS annual meeting has not been an issue for a number of years. In fact, the TMS 2014 Annual Meeting \& Exhibition (TMS2014), taking place February 16-20, 2014 in San Diego, California, set a new record for submitted abstracts. As of press time, nearly 4,000 presentations were scheduled within 385 sessions and nearly 70 symposia, with topics ranging from extraction, recycling, and light metals production to physical and mechanical properties, shaping and forming, highperformance applications, and energy storage, to name but a few.

Enriched by special lectures and vendor exhibits, Moody said that TMS2014 covers "the full life cycle of minerals, metals, and materials," while observing that a number of common trends and issues cut across much of the programming. "Continuing to deliver advances in understanding, predicting, and implementing costeffective solutions is a challenge that all disciplines must address," he said. Other themes include "the coupling of integrated computational materials engineering (ICME) and experimental developments," as well as the impact of advances in characterization, "from structure to deformation and fracture of materials."

While a positive development, the growing volume of interest in presenting and participating in a TMS annual meeting has not been without its complications, from creatively managing space-limited venues to "ensuring our core constituencies are well-served, while programming the latest in emerging topics," explained Moody. A very productive strategy for achieving inclusion and balance has been a commitment "to making posters a highly visible and essential part of the annual meeting," Moody said. "They provide a unique opportunity for in-depth, one-on-one discussions afforded by no other format."

Starting with TMS2014, a few more straightforward, but impactful, changes will make it easier for attendees to take better advantage of all that the meeting has to offer. Key among those is making start and stop times con- 


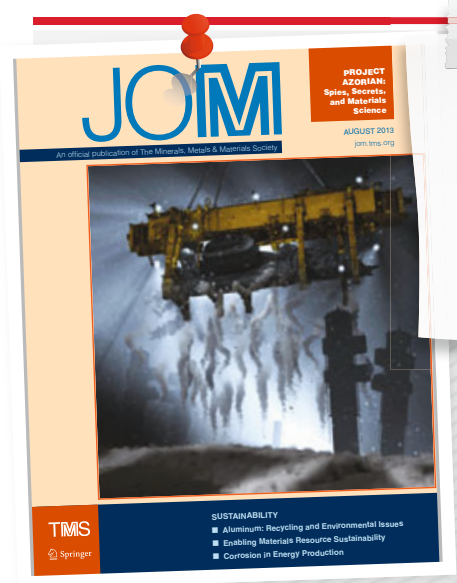

\section{Book Passage to the} SMD LUNCHEON AND

\section{"SHIPWRECK" SYMPOSIUM}

A refitted Structural Materials Division (SMD) Luncheon will sail into San Diego in grand style on Wednesday, February 19. Rajiv S. Mishra, SMD Chair, believes that reintroducing the luncheon after a long absence will fill a need expressed by many division members. "A key goal is to give division leaders and volunteers an opportunity for casual conversation on key issues," he said. "It is very important for our members to be engaged and this will be an excellent venue for facilitating that."

The topic for this year's luncheon echoes the seafaring traditions of the San Diego location, with Gerhard Fuchs, University of Florida, expanding on the popular August 2013 JOM article, "Cold War Thriller Brings Classroom Theory to Life." The focus of Fuch's talk is Project Azorian, a real-life espionage tale of a lost Soviet nuclear submarine and an ambitious, covert engineering feat, kept secret for years, complicated by metallurgical failure. Immediately following the luncheon will be a special showing of the theatrical documentary, Azorian:The Raising of the K-129. Kicking off this exploration of ghost ship myth and metallurgy will be "The Materials Science of Shipwrecks," a special symposium sponsored by the SMD set to begin the morning of February 19. The symposium will feature talks from experts on the materials and metallurgical issues associated with some of history's most notorious nautical disasters. "This should be a must-attend event for everyone involved with any aspect of structural materials," said Mishra.

The symposium and documentary showing are open to all TMS2014 attendees. Tickets for the SMD luncheon must be reserved through the TMS2014 Registration Form.

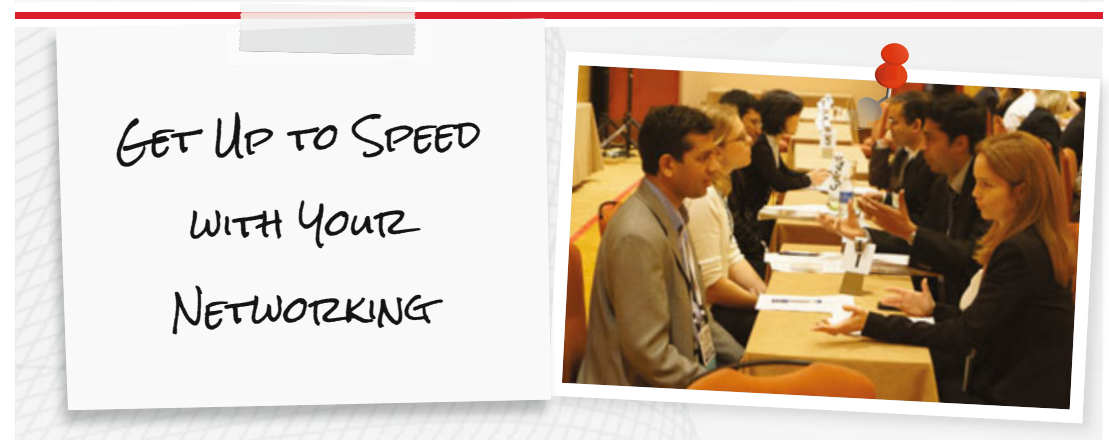

TMS is opening up its Speed Networking Luncheon to all TMS2014 attendees on Monday, February 17. This facilitated event gives participants a chance to connect with up to ten different colleagues in about an hour. Luncheon attendees are matched with networking "partners" according to a questionnaire of professional interests completed ahead of time. A customized schedule received at the beginning of the luncheon outlines the background of each partner, eliminating the need to use precious networking time on details.

Last year's Speed Networking Luncheon, offered only to TMS volunteer leaders, garnered rave reviews. "I feel like I got through the entire TMS annual meeting week in an hour," commented Cindy Belt, an energy management consultant. Speed Networking reservations must be made through the TMS2014 registration form. Proceeds benefit the TMS Foundation. sistent across all sessions, as well as establishing fixed times for presentations. "This will enable more attendees to participate in the many activities, functions, and events that make up a TMS annual meeting," said Moody. "Our intent is that it will increase the opportunities for discussion, networking, collaborations, and friendship.'

Efforts to give attendees access to as many aspects of the TMS annual meeting experience as possible is particularly critical in these days of constrained travel for many professionals, noted Elizabeth Holm, 2013 TMS President. "Most attendees should be able to achieve many of their scientific and travel goals at TMS2014," she said. "This is largely because development of the meeting trickles up from the community of TMS member volunteers, rather than down from a small group of individuals who are deciding what is best for everyone. As a result, TMS2014 offers a vast and

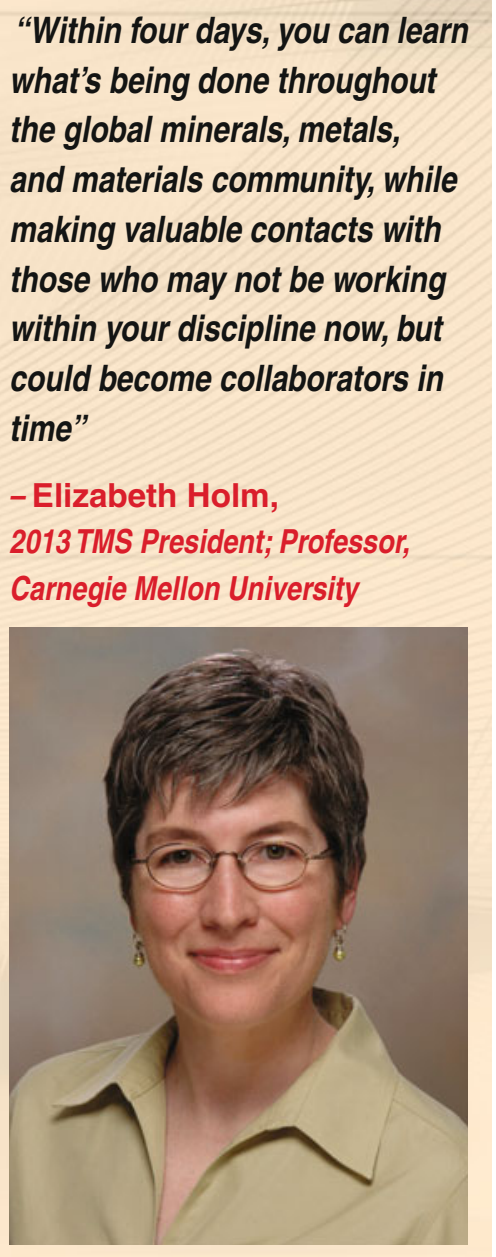


diverse technical program, as well as meaningful networking opportunities in both structured and informal formats. There is also the opportunity for professional enrichment through short courses and other special programs, and you have the ability to contribute to the profession as a whole through participation in our technical and administrative committees. So, within four days, you can learn what's being done throughout the global minerals, metals, and materials community, while making valuable contacts with those who may not be working within your discipline now, but could become collaborators in time."

Holm said the steady increase of international participation - about half the abstracts submitted to TMS2014 were from contributors outside the United States-has also greatly enhanced the value of attendance. "Science and engineering research and development are global endeavors. TMS is very proud to offer a technical program of a caliber that draws professionals from every part of the world," she said. "Not only does this enrich the technical excellence of the program, but it also puts attendees in touch with a worldwide network of colleagues, offering valuable opportunities for collaboration and cooperation."

"These interpersonal aspects of TMS2014 can't be duplicated in any other way," Holm continued. "In one event, you find out about the latest research and developments from throughout the world, and actually talk with the people who are at the top of their field in an area that you are working in, or want to work in someday. This enables you to pursue your technical interests at the highest level once you go home, with the knowledge of how your efforts fit in with the rest of the professional community."

For detailed information on all symposia and presentations, as well as updates on new additions to the meeting program, visit the TMS2014 website at www.tms.org/tms2014. Go to the Registration \& Travel tab of the website to secure optimal housing rates and to register by January 17 to receive the discounted registration fee.
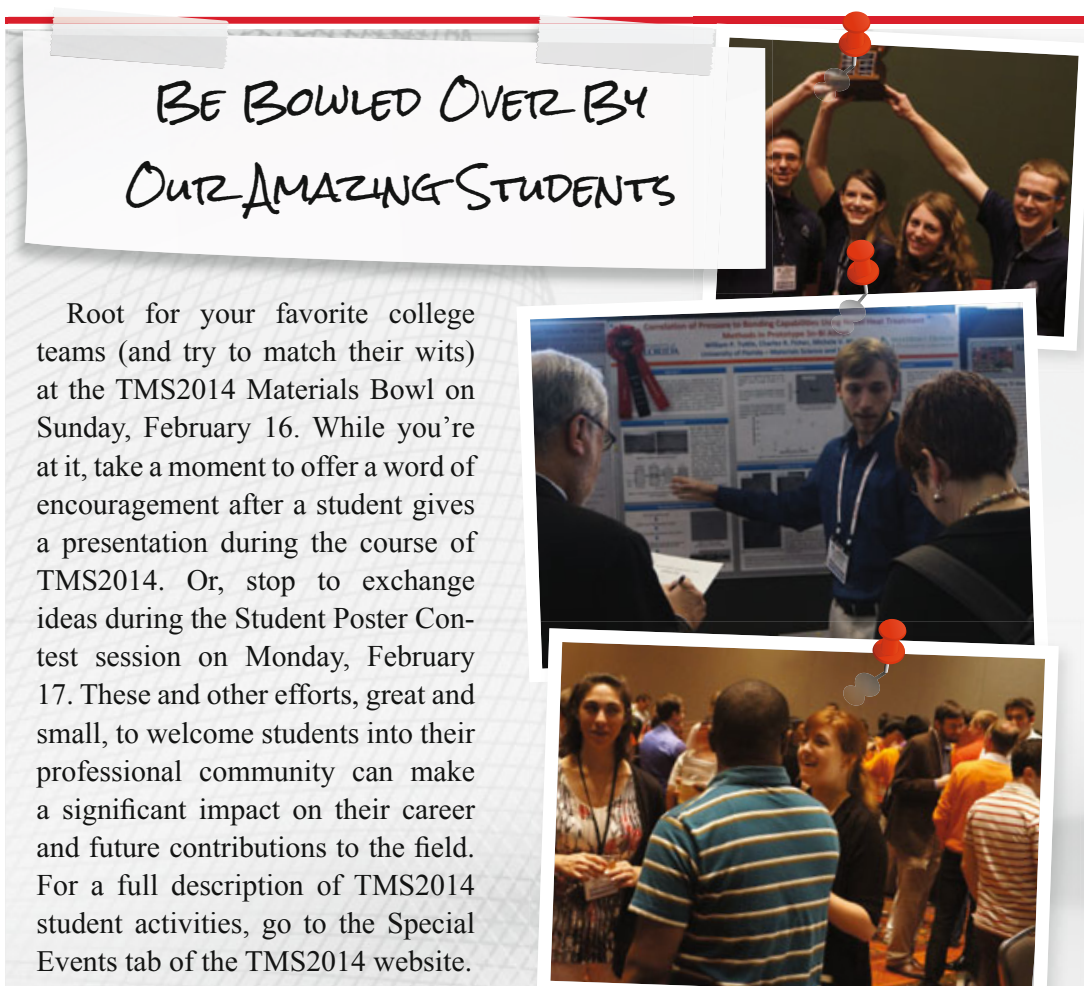
teams (and try to match their wits) at the TMS2014 Materials Bowl on Sunday, February 16. While you're at it, take a moment to offer a word of encouragement after a student gives a presentation during the course of TMS2014. Or, stop to exchange ideas during the Student Poster Contest session on Monday, February 17. These and other efforts, great and small, to welcome students into their professional community can make a significant impact on their career and future contributions to the field. For a full description of TMS2014 Events tab of the TMS2014 website.

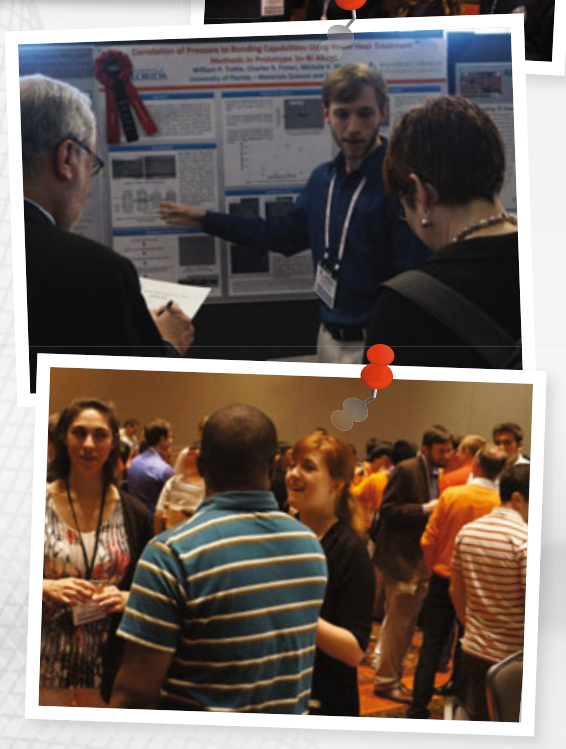

\section{Aluminum Keynote:}

\section{How will we Move to the Next \\ INNOVATION S-CURVE?}

Over the last several decades, research and development (R\&D) within the aluminum industry has suffered from such factors such as cost cutting and "rationalization" following company mergers and takeovers. A panel of leading experts from industry and academia will examine the potential consequences in "Innovation in the Aluminum Industry Supply Chain-How Will We Move on to the Next S Curve," the TMS2014 Aluminum Keynote session set for Monday, February 17. The focus of this always-popular TMS annual meeting event will be on strategies to achieve "the critical mass of $\mathrm{R} \& \mathrm{D}$ required for breakthroughs that can lift industry environmental and energy efficiency performance to maximize future growth potential," according to Barry Sadler, Managing Director, Net Carbon Consulting Pty. Ltd. and session organizer. Discussion will include possible funding models, the roles of international cooperation and government funding, and insight from a comparative metals industry.

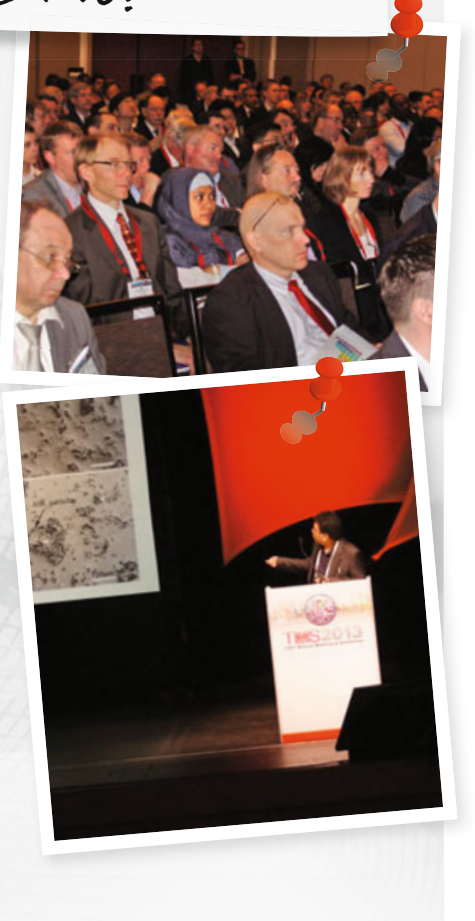



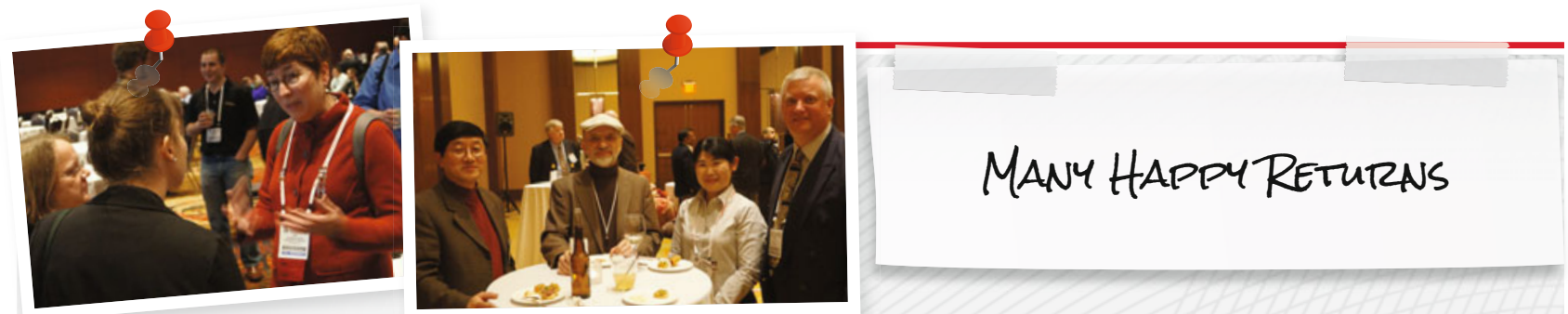

TMS members who have attended 10 or more consecutive annual meetings will have a chance to renew acquaintances at the TMS2014 Repeat Attendee Reception. Last year marked the first year for the invitation-only event, and James J. Robinson, TMS executive director, said it was particularly well received. "These folks are the infrastructure of the annual meeting, and I was pleased to be able to thank them in this small way," he said. In addition to complimentary drinks and appetizers, repeat attendees will receive a commemorative pin to mark their attendance record.

Also returning to TMS2014 is the Networking Meeting of the Membership, scheduled for Sunday, February 16. More than 300 annual meeting attendees converged on the event last year for light snacks, informal discussion, and a relaxed presentation of the previous year's highlights. There is no charge to attend this session, but pre-registration is required through the TMS2014 Registration Form.
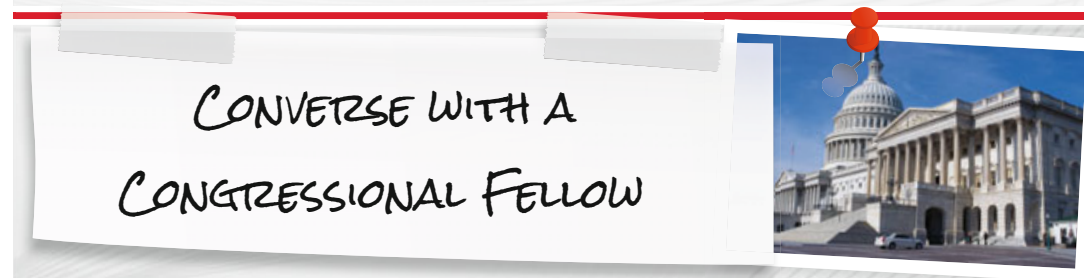

As bewildering as United States policy making can be, it also offers an opportunity to make a difference in how resources supporting the continued advancement of minerals, metals, and materials will be managed. The TMS-Materials Research Society (MRS) Congressional Science and Engineering Fellowship offers accomplished scientists and engineers a unique and valuable perspective on how to contribute to the policy process in a meaningful way. Interested TMS members can get an insider account of the fellowship experience at "Why Scientists Are Needed In Policy Makinga Face-to-Face with Congressional Fellows" on Monday, February 17, 3:30 p.m., at the TMS Information Center in the Exhibition Hall.
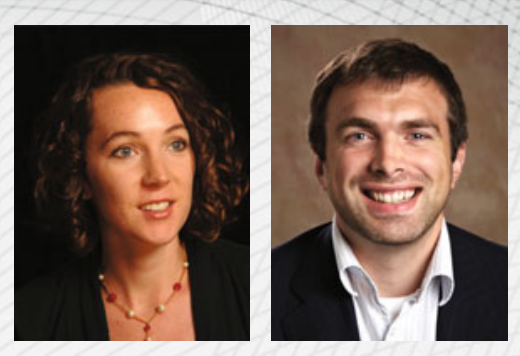

Megan Brewster (left) is the 2013-2014 TMS/MRS Congressional Fellow. She has recently accepted placement on the U.S. Senate Committee on Energy and Natural Resources and will be available to discuss her experiences. Edward D. Herderick, Public \& Governmental Affairs Director on the TMS Board, will also be on hand to share his perspectives as a past Congressional Fellow.
TMS is offering nearly a dozen workshops, tutorials, and short courses on Sunday, February 16, prior to the start of TMS2014 technical programming on the following day. Be sure to reserve your place at the program of your choice through the TMS2014 registration form. At press time, available continuing education opportunities included:

- 10th Annual Lead Free Solder and Interconnect Technology Workshop

- Fundamentals of Friction Stir Welding and Processing

- Furnace Systems Technology Workshop

- Grain Refinement of Aluminum and Magnesium Alloys: Theory and Practice

- Incorporating Life Cycle Assessment in Operational Decision-Making

- Neutron and X-Rays: Tutorial on Sources, Instrumentation, and Scattering

- Pot Ventilation \& Dry Scrubbing Operations for Aluminum Smelters

- Proper Anode Baking Furnace Operations: How and Why

- Radiation Effects in Oxide Ceramics and Novel LWR Fuels

- Sustainability and Mineral Resources

- Theory of Constraints: Tools and Tactics for Creating Business Value in Aluminum Smelters and Other Process Industries

For course details and instructor biographies, go to the Continuing Education tab of the TMS2014 website at www.tms.org/tms2014.

\section{KICKSTART TMS2D14 WITH A}

\section{continuing Eoucation course}

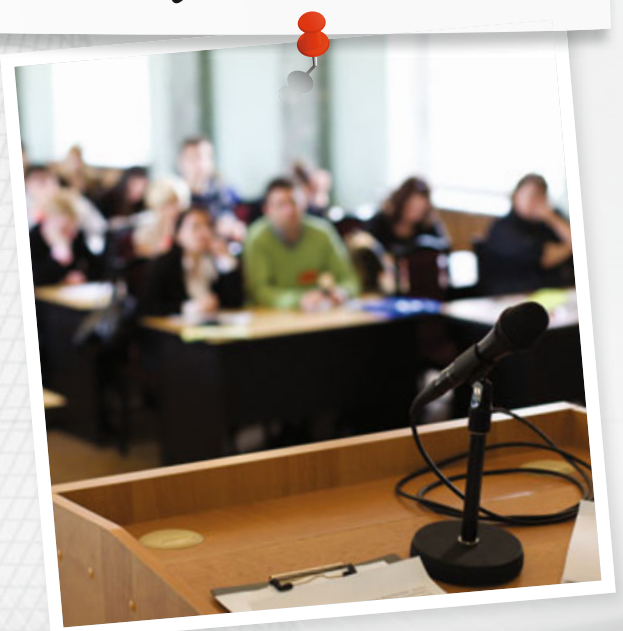




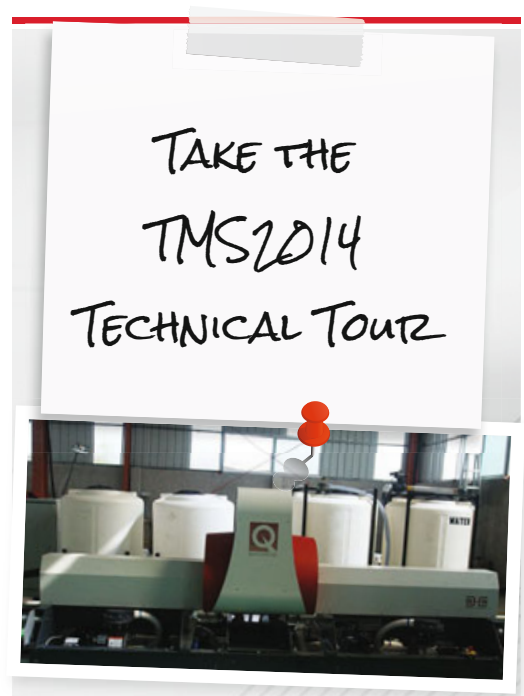

(Above) Quantum Design developed and Installed its first superconducting high-gradient magnetic separator in China.

New for TMS2014 is the chance to expand on the session-room learning with a firsthand look at how innovative concepts and approaches are being applied in the marketplace. Quantum Design will open its doors to TMS2014 attendees for a tour of its San Diego manufacturing and testing facilities, applications laboratory, and whole-building, high-pressure helium recovery and liquefaction system. Founded in 1982, Quantum Design specializes in automated temperature and magnetic field testing platforms for materials characterization. Space is limited and reservations must be made through the TMS2014 registration form.

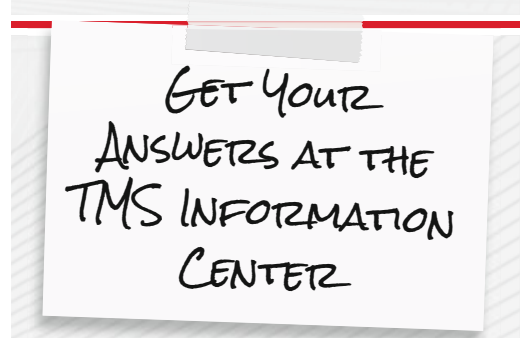

New for TMS2014 is the TMS Information Center in the Exhibition Hall. The Center consolidates all things TMS in one convenient location. Make sure to stop by to find how to get the most out of your TMS member benefits, learn about TMS's technical initiatives, be inspired by the work of the TMS Foundation, and discover new opportunities as a TMS volunteer.
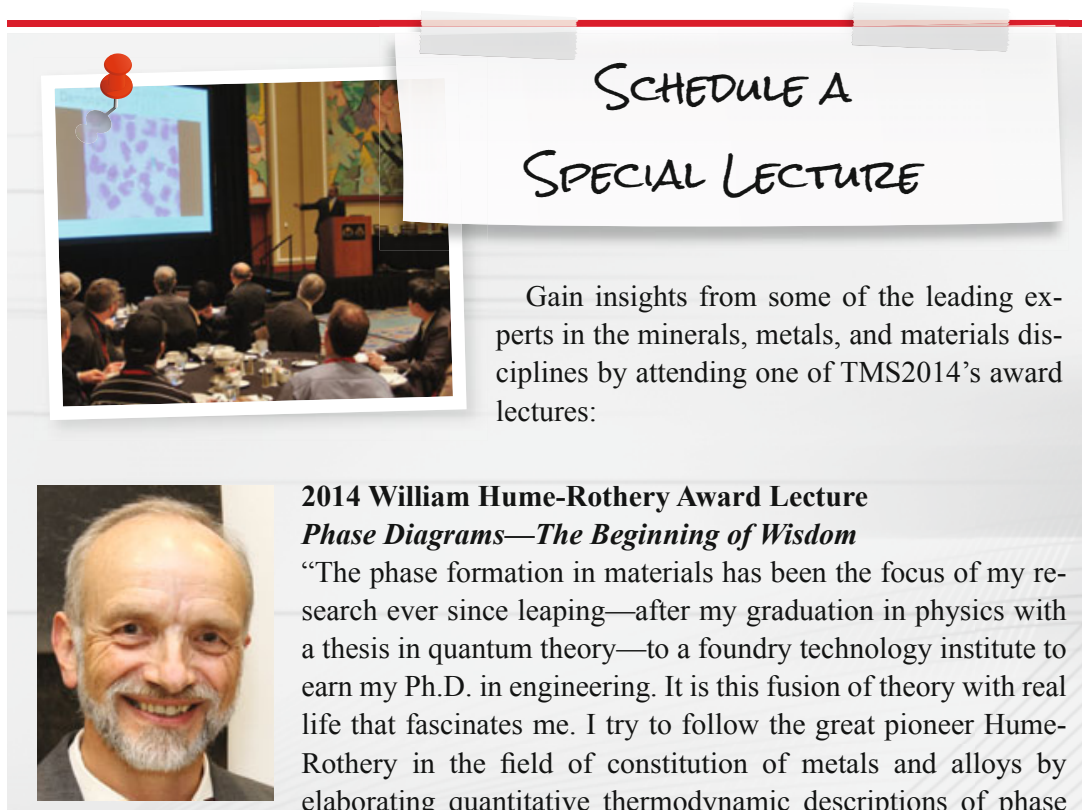

2014 William Hume-Rothery Award Lecture Phase Diagrams-The Beginning of Wisdom

"The phase formation in materials has been the focus of my research ever since leaping - after my graduation in physics with a thesis in quantum theory - to a foundry technology institute to earn my Ph.D. in engineering. It is this fusion of theory with real life that fascinates me. I try to follow the great pioneer HumeRothery in the field of constitution of metals and alloys by elaborating quantitative thermodynamic descriptions of phase stability in truly multi-component alloys with applications to phase and microstructure formation in processing technology. I am looking forward to the Hume-Rothery Award Symposium at TMS2014 and to stimulating discussions at the TMS annual meeting, which I enjoyed so many times."

-Rainer Schmidfetzer, Clausthal University of Technology; 2014 William Hume-Rothery Award Winner

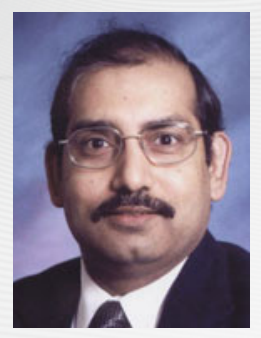

Extraction \& Processing Division Distinguished Lecture How Critical Is Recycling for Critical Materials' Sustainability?

"Growing global population will put a tremendous pressure on resource availability in the very near future. Demand will begin to outstrip the supply for most types of materials and commodities used by us. The quality and grade of many natural resources are also deteriorating, making extraction and processing even more challenging. These societal challenges can only be managed by proper materials and resource recovery, recycling, reuse, and remanufacturing."

—Brajendra Mishra, Colorado School of Mines; 2014 EPD Distinguished Lecturer

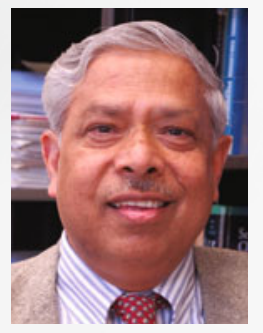

Institute of Metals/Robert Franklin Mehl Lecture Frontiers in Thin Film Epitaxy and Novel Nanostructured Materials

"As a great fan of Professor Mehl, this award holds a special significance for me. And, TMS has served me well in pursuing my passion to use materials science and technology for the greater good of the society Our recent research in nanomaterials stand to revolutionize the modern era as we must do more with less and less to conserve and sustain our dwindling resources of critical materials."

— Jagdish Narayan, North Carolina State University, 2014 Institute of Metals/Robert Franklin Mehl Award Winner

To access the abstracts and other information on these and other special programming opportunities, visit the Special Events tab of the TMS2014 website. 


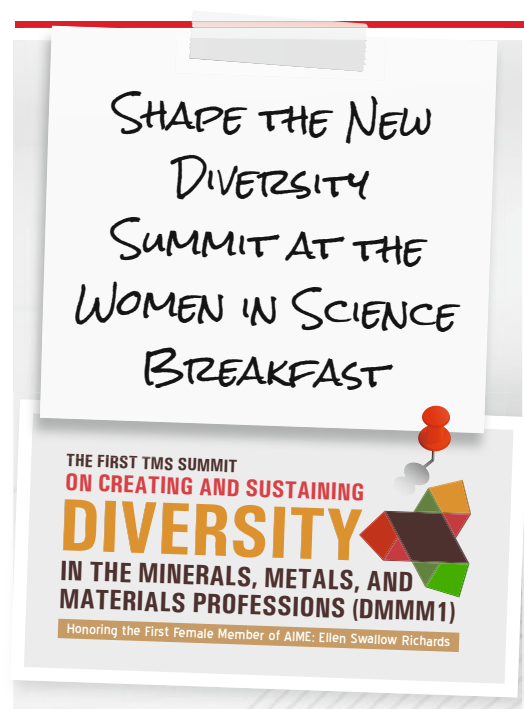

The energy generated by the informal, roundtable discussions of the annual TMS Women in Science Breakfast will be channeled this year to inform the first Summit on Creating and Sustaining Diversity in the Minerals, Metals, and Materials Professions, slated for July 29-31 in Washington, D.C. TMS is coordinating the efforts of several associations within the science and engineering community to organize this event.

Elizabeth Holm, 2013 TMS president, explained that breakfast participants will be called on "to help us understand the most important topics that we need to develop and make sure the summit's workshops and presentations are addressing what needs to be addressed."

Holm said that the breakfast format will not change except for having a member of the summit organizing committee available at each table to take notes. "We are building on what we've done in past years by having frank, productive discussions on career issues such as work life balance and finding mentors," she said. "I believe it will be of benefit to the people attending the breakfast, as well as those who will participate in the summit."

Tickets for the Women in Science Breakfast must be purchased through the TMS2014 registration form. For additional information on the Diversity Summit, visit the website at http://www.tms.org/meetings/2014 /diversity/home.aspx.

\section{A Faster, Easier Collecteo Proceedings Process}

One of the most valuable benefits of registering for a TMS annual meeting is free, exclusive access to the published collected proceedings. Last year marked the first time that the proceedings were delivered online, rather than on CD-ROM. With the input of many attendees from last year's meeting, TMS has developed an even more userfriendly process for accessing TMS2014's collected proceedings.

- On the TMS2014 meeting registration form, attendees will have the option to purchase a DVD for an additional \$25.

- Approximately one week prior to TMS2014, pre-registered attendees will be sent a URL and receive access information for the proceedings upon verifying their registration. On-site registrants will receive the access information at the time they register.

- The proceedings landing page will give attendees three options for accessing content: (1) A single PDF file that contains all proceedings content in one bundle; (2) separate PDF files for each proceedings publication; (3) complimentary access to the Wiley Online Library for downloads of individual articles.

- None of the PDF files will require unique software. Users who are able to open standard PDF files will be able to access the proceedings files in the same way.

- Attendees will have access to an on-site help location at the meeting.

- Free access to the 2014 collected proceedings will be available to TMS2014 attendees for six months after the first day that access is granted. Once the six months have elapsed, standard TMS member pricing will take effect.

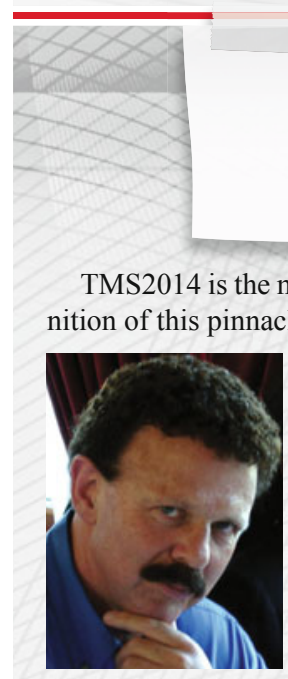

Robert O. Ritchie

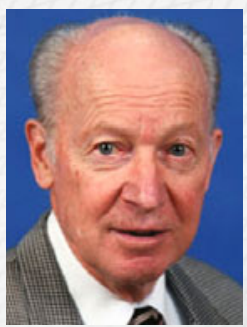

Karl A. Gschneidner, Jr.

\section{HONOR TWO ACTA}

\section{materialia winnets}

Check the TMS2014 website at www.tms.org/tms2014 for presentation updates for both of these award winners. 


\section{LEARN FROM THE LEGENDS}

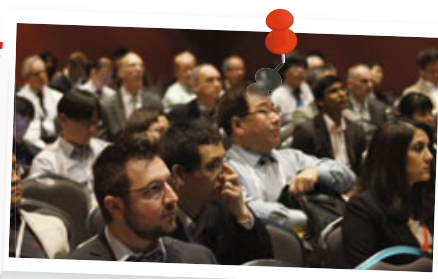

TMS2014 features four symposia honoring the work and contributions of some of the most influential minds in minerals, metals, and materials science and engineering. While highlighting the accomplishments of extraordinary individuals, these events also provide a unique forum for learning and networking that benefits meeting attendees at all career stages. "For young professionals, honorary symposia offer opportunities to meet the leaders in their field, build networks and contacts, and gain exposure," said Neville Moody, TMS Program Committee Chair. "For those in mid-career, the symposia set the stage for discussions on the current state of understanding, latest advances, and future directions. And, for senior career professionals, honorary symposia enable discussion of the evolution of the field and the impact of their contributions over the years."

Be sure to check the Programming tab of the TMS2014 website for additional details on the honorary symposia and related events. Use the following list as a quick reference to start planning:

A Lifetime of Experience with Titanium Alloys: An SMD Symposium in Honor of Jim Williams, Mike Loretto, and Rod Boyer The successful and widespread industrial use of titanium alloys can be traced, in large part, to the work of this symposium's three honorees. "Honoring their contributions in an open forum will remind the new era of engineers of the good work done in the past that doesn't necessarily come up on a Google search," commented Adam L. Pilchak, Materials Research Engineer, U.S. Air Force Research Laboratory, Materials and Manufacturing Directorate, and symposium organizer. "In addition, we hope that recalling their accomplishments and commitment to education will inspire the students in attendance to do

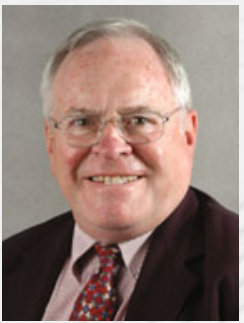

Jim Williams

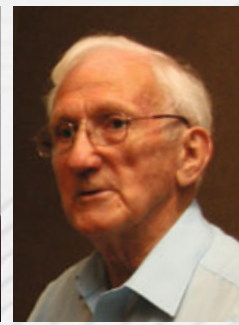

Mike Loretto

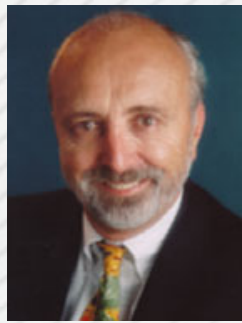

Rod Boyer great things."

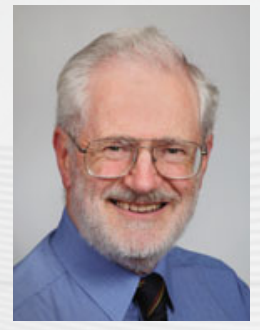

David G.C. Robertson

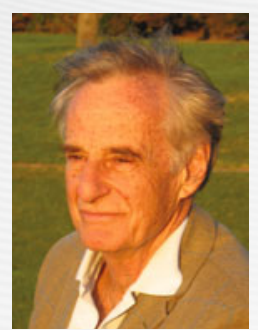

Marc Meyers

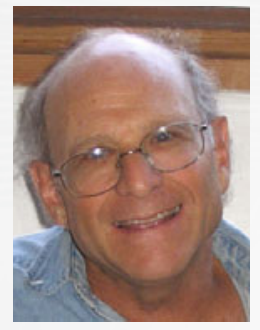

Michael I. Baskes
Celebrating the Megascale: An Extraction and Processing Division (EPD) Symposium in Honor of David G.C. Robertson

Metal producers are looking to economies of scale — with some plants reaching the megascale - as a strategy to remain profitable within an unpredictable global economy, while minimizing environmental impact and energy consumption. The benefits and challenges associated with this will be examined within the context of David G.C. Robertson's dedication to educating highly skilled metallurgical professionals, as well as to the engineering of all types and sizes of metallurgical processes, particularly those involving molten metals.

\section{Dynamic Behavior of Materials VI-An SMD Symposium in Honor of Professor Marc Meyers}

As noted by symposium organizers, George T. (Rusty) Gray III, Laboratory Fellow, Los Alamos National Laboratory, and Naresh Thadhani, Professor and Chair, School of Materials Science and Engineering, Georgia Institute of Technology, "This symposium will provide a broad snapshot of the state of our knowledge of material behavior under extreme loading environments with leading national and international leaders in the field presenting their current research, coupled with insights into how Professor Meyers has influenced the direction of this field over the past four decades."

Progress Towards Rational Materials Design in the Three Decades Since the Invention of the Embedded Atom Method: A Materials Processing \& Manufacturing Division (MPMD) Symposium in Honor of Dr. Michael I. Baskes

Recent advances have made the realistic simulation of materials behavior possible. Decades ago, modeling of materials at the atomic level used simple pair potentials, which did not provide an accurate description of elastic properties or the formation of free surfaces. Michael Baskes overcame these limitations with the development of the Embedded Atom Method (EAM), helping to usher in a new era of materials design. This symposium will examine the impact of EAM, as well as Baskes's many other pioneering contributions, while looking forward to research that builds on his work to establish strong connections between experiments and computational modeling across length and time scales.

For additional background, look for the January 2014 JOM feature profiling each of these honorees and their contributions. 